\title{
Impact of pharmacist interventions in older patients: a prospective study in a tertiary hospital in Germany
}

This article was published in the following Dove Press journal:

Clinical Interventions in Aging

26 September 2016

Number of times this article has been viewed

\section{Cortejoso'}

RA Dietz ${ }^{2}$

G Hofmann'

$M$ Gosch $^{2}$

A Sattler'

'Department of Pharmacy,

2Department of Geriatrics, Hospital

Nuremberg, Paracelsus Medical

Private University Nuremberg,

Nuremberg, Germany
Correspondence: Lucía Cortejoso

Department of Pharmacy,

Universitätsklinikum Carl Gustav

Carus Dresden, Fetscherstrasse 74,

$0 \mid 307$ Dresden, Germany

Tel +49 35I 4588843

Email lucia.cortejoso@uniklinikumdresden.de
Background: Inappropriate pharmacotherapy among older adults remains a critical issue in our health care systems. Besides polypharmacy and multiple comorbidities, the age-related pharmacokinetic and pharmacodynamic changes may increase the risk of adverse drug reactions and medication errors.

Objective: The main target of this study was to describe the characteristics of pharmaceutical interventions in two geriatric wards (orthogeriatric ward and geriatric day unit) of a general teaching hospital and to evaluate the clinical significance of the detected medication errors.

Materials and methods: The study was conducted between August 2014 and October 2015 and was based on a triple approach that included validation of medical orders, medication reconciliation at patients' admission, and a predischarge planning appointment with the patient. The validation of medical orders was based on analyzing the suitability of the drugs prescribed, the drug dose depending on the patient's characteristics, the presence of contraindications and interactions between drugs, and the proposal of alternative drugs included in the hospital formulary.

Results: A total of 2,307 interventions associated to a medication error in 15,282 medical orders for 1,859 older patients were recorded. The greater part of the interventions carried out on the orthogeriatric ward at admission and at discharge were due to omission of a drug in the medical order $(20.0 \%)$ and clinically significant interactions requiring monitoring $(30.4 \%)$, respectively. The main factor triggering pharmacist's recommendations on the geriatric day unit was clinically significant interactions $(21.1 \%)$. With regard to the clinical severity of the detected errors, $68.1 \%$ were considered significant, $24.8 \%$ were of minor significance, and $7.2 \%$ were clinically serious.

Conclusion: Our findings show the importance of clinical pharmacist involvement in the optimization of pharmacotherapy in older adults, ensuring that they receive effective, safe, and efficient drug therapy.

Keywords: older adults, medication errors, pharmacist interventions

\section{Introduction}

Polypharmacy and inappropriate pharmacotherapy among older adults are known to increase the risk of adverse drug reactions due to drug-drug interactions, drug-disease interactions, and medication errors. A medication error is defined as

any preventable event that may cause or lead to inappropriate medication use or patient harm while the medication is in the control of a health care professional, patient, or consumer. ${ }^{1}$ 
In addition to increases in medications and comorbidities, the age-related pharmacokinetic and pharmacodynamic changes may further increase the risk of adverse drug reactions in the older adults. It has been estimated that one in ten older adults experience an adverse drug reaction leading to or during hospitalization. ${ }^{2}$ In a recent study, it was shown that older adults in Germany are at the top of pharmaceutical consumers in Europe. ${ }^{3}$ Recently, the term deprescribing has been developed to describe a process required for the safe and effective cessation of inappropriate medications ${ }^{4}$ that results in a significant positive effect on health in the elderly. ${ }^{5}$

Over the last few years, the role of the pharmacists has expanded with the implementation of clinical pharmacy. Pharmacist interventions are nowadays considered as a valuable input in the patient care process by rationalizing the pharmacotherapy and reducing medication errors. However, patient-centered clinical pharmacy services are still poorly developed in much of Europe. ${ }^{6}$ In other countries such as the USA and the UK, clinical pharmacists are very much involved in multidisciplinary teams by actively participating in the rounds and in the decisions regarding the pharmacotherapy of the patients. Therefore, reporting European studies in this context is crucial to assess the necessity of clinical pharmacy activities.

Studies from inpatient settings suggest that the inclusion of a pharmacist in the health care team could reduce mortality and improve outcomes. ${ }^{7,8}$ It is well known that medication errors are a major problem in transitions of care. ${ }^{9,10}$ Since older patients account for a high percentage of these transitions, this patient group is most vulnerable to suffer from poor-quality transitional care. ${ }^{11}$ Many studies have also shown that pharmacists can improve the accuracy of information on patients' medication use if the pharmacist carries out medication reconciliation at hospital admission, ${ }^{12-14}$ taking into account that incomplete medication histories obtained at admission account for $>25 \%$ of prescribing errors in hospitals. ${ }^{15}$

The correct administration technique for the various dosage forms (eg, inhalers, injection devices, and eye drops) is a crucial issue in older patients with deficient ergonomic and audiovisual abilities. Therefore, the administration of medicines by the elderly is often a cause of medication errors and reduced therapeutic effects. In this context, predischarge planning appointments in which pharmacists ensure the correct administration of drugs by patients or their relatives have been shown to be a reasonable approach. ${ }^{16}$
The Federal Department of Health in Germany has decided in July 2015 that all patients taking three or more prescribed medicines have the right to get a medication plan either from a doctor or from a pharmacist. This new law is intended for an increased safety with regard to the pharmacotherapy in the ambulant sector and will come into effect in autumn 2016.

The primary objective of this study was to describe the characteristics of pharmaceutical interventions in two geriatric wards of a general teaching hospital and to evaluate the clinical significance of the detected medication errors. The secondary objective was to compare the number of drugs at admission and at discharge of the patients who were admitted in an orthogeriatric ward.

\section{Materials and methods}

Data were collected prospectively in the context of a project about quality assurance and then anonymated and analyzed retrospectively. Clinical pharmacists validated the medical orders on an orthogeriatric ward in Klinikum Nürnberg at discharge (from September 2014 to October 2015, 5 days per week), at admission (from August 2014 to October 2015, 3 days per week), and in a geriatric day unit at discharge (from July 2015 to October 2015, 2 days per week). The geriatric ward has 24 beds, and the patients are treated by an orthogeriatric comanagement model. ${ }^{17}$ The day unit has the capacity and resources to treat 48 patients, who attend from 8 am until $4 \mathrm{pm}$ to receive multidisciplinary treatment by physicians, nurses, physiotherapists, speech therapists, masseurs, and psychologists. In comparison with the orthogeriatric ward, the pharmacist worked in situ, spending her complete working day on the day unit. The patients included in our study were limited to those 65 years or older, who were taking one or more prescription drugs. Our validation of medical orders at admission and discharge was based on analyzing the suitability of the drugs prescribed for each indication, the drug dose depending on the patient's characteristics and adjustments due to age, renal, and hepatic impairment, and the existence of contraindications and interactions between drugs and proposal of alternative drugs when they were not included in the hospital formulary. The sources used for this validation were the summary of product characteristics of the drugs and the following databases: Micromedex ${ }^{\circledR}$, ABDA Datenbank $^{\circledR}$, and AiDKlinik ${ }^{\circledR}$. The interventions were made orally on the day unit and at the patients' discharge on the orthogeriatric ward and written at the patients' admission on this ward. After their daily activity on the orthogeriatric ward, 
the pharmacists registered the following variables: number and type of interventions, total number of medicines at admission and at discharge, number of medication reconciliations carried out at admission, and number of medication plans with information at discharge. On the day unit, the number and type of interventions were recorded, as well as the number of medication plans. All the variables were systematically registered in a Microsoft Excel database.

The information resources used for the medication reconciliation at admission were the medication plans from general practitioners or nursing homes, medication from recent hospital stays, and, when possible, interviews with the patient and/or patient's relatives. After that, the pharmacist registered electronically the drugs at admission and proposed the switching to the drugs included in the formulary based on conversions involving the same active drug or a therapeutic equivalent drug. This process was carried out through a standardized document, which is linked to the hospital's electronic medical record system. ${ }^{18}$ On this document, there is a field for pharmacists' observations so that the physicians could know if there was any problem with the medication at admission.

Patients and their relatives had the chance to address their concerns related to the use of their medications, which were discussed before discharge, at the time when the pharmacists explained to them their medication plans. The drawing up of the medication plans was carried out using the AiDKlinik software on the day prior to discharge.

The severity of the medication error was analyzed using a slightly modified version of the scale developed by Overhage et al, generating a categorical variable with five categories: 1) potentially lethal; 2) serious; 3) significant; 4) minor; and 5) no error (Table 1). This classification has already been used by other authors in a pediatric population with very good results. ${ }^{19}$ In the analysis, we distinguished the interventions made in case of detection of a medication error from those interventions that were only informative. As indicator of pharmacists' activity, the number of “interventions/medical orders" was used.

The total number of drugs at discharge on the orthogeriatric ward was corrected by not considering the drugs that were prescribed during hospitalization, which were going to be stopped by the family doctor a few days after discharge from the hospital. These drugs were analgesics, lowmolecular weight heparins, and laxatives as comedication with opioids.

The descriptive variables were analyzed in terms of percentage, median, and standard deviation. For the quantitative
Table I Reasons for intervention and severity of the medication error

Potentially lethal

High potential for life-threatening adverse reactions

Potentially lifesaving drug at a dosage too low for the disease being treated

High dosage (more than ten times the normal dosage) of drug with narrow therapeutic index

Serious

Route of administration could lead to severe toxicity

Low dosage of drug for serious disease in patient with acute distress High dosage (four to ten times the normal dosage) of drug with narrow therapeutic index

Dosage could result in potentially toxic concentrations

Drug may exacerbate the patient's condition (warnings or contraindications)

Misspelling or mix-up in medication order could lead to dispensing of wrong drug

Documented allergy to a drug

High dosage (more than ten times the normal dosage) of drug with normal therapeutic index

Omission of pretest for drug hypersensitivity

Drug without indication

Interaction: association contraindicated

Error in the content of a secondary medicines package/refill error Significant

High dosage (I.5-4 times the normal dosage) of drug with narrow therapeutic index

Drug dosage too low for patient's condition

High dosage (1.5-10 times the normal dosage) of medication with normal therapeutic index

Therapeutic duplication

Inappropriate dosage interval

Drug omitted from the medical order

Route of administration that can lead to mild toxicity

Interaction: clinically significant, requires monitoring

Error in the switching to a medication included in the hospital

drug guide

Transcribing error in the administration chart

Error in the handling of a pharmaceutical form

Minor

Incomplete information on the medical order

Inappropriate dosage form

Nonformulary drug

Noncompliance with standard formulations and hospital policies

Illegible, ambiguous, or nonstandard abbreviations

Error in the time of administration

Medical chart documentation error

No error

Information requested by physician or other health care professional from pharmacist

Clarification of medical order or information request

Medication plan explanation

Administration information for oral/subcutaneous/inhalative medicines Medication reconciliation at the hospitalization

Switching to a medication included in the hospital drug guide 
variables, a chi-square test of independence was applied. The statistical analysis was performed using the program $\mathrm{R}$ Version 3.0.2. $P<0.05$ was chosen as the level of statistical significance.

No informed consent was necessary as the pharmacists' activity was considered daily practice on the ward, and therefore, the study was not reviewed by the local research ethics committee. The data collected were uniquely used for the purpose of scientific publication.

\section{Results}

A total of 2,307 interventions associated to a medication error in 15,282 medical orders for 1,859 older patients were recorded in the three different settings (862 interventions in 3,110 medical orders for 435 patients admitted on the orthogeriatric ward; 1,251 interventions in 10,942 medical orders for 1,294 patients discharged from the orthogeriatric ward; and 194 interventions in 1,230 medical orders for 130 patients discharged from the geriatric day unit). This means that 0.9 interventions were made for every ten medical orders.

The age of the patients admitted on the orthogeriatric ward was $82 \pm 8$ years, and $72.6 \%$ of these patients were women. On the geriatric day unit, the majority of the patients were also women $(66.9 \%)$ and their age was $79 \pm 6.5$ years.

The greater part of the interventions associated with medication errors carried out on the orthogeriatric ward at admission were due to omission of a drug in the medical order $(20.0 \%, \mathrm{n}=172)$, followed by clinically significant interactions that require monitoring $(19.7 \%, \mathrm{n}=170)$, incomplete information on the medical order $(13.7 \%, n=118)$, and overdose of drugs with a normal therapeutic index $(8.5 \%, \mathrm{n}=73)$ (Table 2). Medication reconciliation was carried out for 457 patients who were admitted on this ward within the study period, and 261 long-term medications were switched to therapeutic equivalents included in the hospital formulary.

With regard to the pharmacists' activity on the orthogeriatric ward at patients' discharge, the most frequent interventions were due to clinically significant interactions requiring monitoring $(30.4 \%, n=380)$, incomplete information on the medical order $(14.3 \%, \mathrm{n}=179)$, drugs omitted from the medical order $(10.3 \%, \mathrm{n}=129)$, and transcribing error in the administration chart $(8.2 \%, \mathrm{n}=103)$ (Table 3$)$. In this setting, the overdose medication errors comprised $6.4 \%(n=172)$ of all clinical interventions. A total of 2,389 administration explanations for oral, subcutaneous, and inhaled medicines were conducted, and 252 medication plans were written, explained, and given to the patients at discharge.
Table 2 Interventions carried out on the orthogeriatric ward at admission

\begin{tabular}{|c|c|c|}
\hline Interventions & $\mathbf{n}$ & $\%$ \\
\hline \multicolumn{3}{|l|}{ Associated with errors } \\
\hline Drug omitted from the medical order & 172 & 20.0 \\
\hline $\begin{array}{l}\text { Interaction: clinically significant, requires } \\
\text { monitoring }\end{array}$ & 170 & 19.7 \\
\hline Incomplete information on the medical order & 118 & 13.7 \\
\hline High dosage (1.5-10 times the normal dosage) & 73 & 8.5 \\
\hline \multicolumn{3}{|l|}{ of medication with a normal therapeutic index } \\
\hline Transcribing error in the administration chart & 69 & 8.0 \\
\hline Drug dosage too low for patient's condition & 48 & 5.6 \\
\hline Medical chart documentation error & 42 & 4.9 \\
\hline Drug without indication & 42 & 4.9 \\
\hline Error in the time of administration & 36 & 4.2 \\
\hline Inappropriate dosage interval & 26 & 3.0 \\
\hline Inappropriate dosage form & 17 & 2.0 \\
\hline $\begin{array}{l}\text { Error in the switching to a medication included } \\
\text { in the hospital drug guide }\end{array}$ & 14 & 1.6 \\
\hline $\begin{array}{l}\text { The drug may exacerbate the patient's } \\
\text { condition (adverse effects or contraindications) }\end{array}$ & 13 & 1.5 \\
\hline Therapeutic duplication & 12 & 1.4 \\
\hline Interaction: association contraindicated & 10 & 1.2 \\
\hline Total & 862 & 100.0 \\
\hline \multicolumn{3}{|l|}{ Not associated with errors } \\
\hline Medication reconciliation at the hospitalization & 457 & 61.8 \\
\hline $\begin{array}{l}\text { Switching to a therapeutic equivalent included } \\
\text { in the hospital drug guide }\end{array}$ & 261 & 35.3 \\
\hline $\begin{array}{l}\text { Clarification of medical order or information } \\
\text { request }\end{array}$ & 13 & 1.8 \\
\hline $\begin{array}{l}\text { Information requested by physician or other } \\
\text { health care professional from pharmacist }\end{array}$ & 9 & 1.2 \\
\hline Total & 740 & 100.0 \\
\hline
\end{tabular}

On the geriatric day unit, the most frequent intervention was once again clinically significant interactions $(21.1 \%, \mathrm{n}=41)$ (Table 3). Other common medication errors in this unit were drugs omitted from the medical order $(14.4 \%, n=28)$, incomplete information on the medical order $(13.9 \%, n=27)$, high dosage (1.5-10 times the normal dosage) of medications with a normal therapeutic index $(11.9 \%, n=23)$, and errors in the handling of pharmaceutical forms $(8.2 \%, n=16)$. In this case, 48 medication plans were written, and a total of 447 explanations for the administration of the drugs were conducted.

On the geriatric day unit, the clinical pharmacist was more frequently requested by physicians and nurses for information related to the pharmacotherapy of the patients in comparison with the orthogeriatric ward at patients' admission and discharge (5.7\% vs $1.2 \%$ and $1.7 \%$, respectively, $P<0.05)$. Similarly, it was on the day unit that the pharmacist asked for more clarification of the medical orders (19.8\% vs $1.8 \%$ and $15.7 \%$ at admission and discharge, respectively, $P<0.05)$. 
Table 3 Interventions carried out on the orthogeriatric ward and on the geriatric day unit at discharge

\begin{tabular}{|c|c|c|c|c|}
\hline \multirow[t]{2}{*}{ Interventions } & \multicolumn{2}{|c|}{ Orthogeriatric ward } & \multicolumn{2}{|c|}{ Geriatric day unit } \\
\hline & n & $\%$ & $\mathbf{n}$ & $\%$ \\
\hline \multicolumn{5}{|l|}{ Associated with errors } \\
\hline Interaction: clinically significant, requires monitoring & 380 & 30.4 & 41 & 21.1 \\
\hline Incomplete information on the medical order & 179 & 14.3 & 27 & 13.9 \\
\hline Drug omitted from the medical order & 129 & 10.3 & 28 & 14.4 \\
\hline Transcribing error in the administration chart & 103 & 8.2 & 6 & 3.1 \\
\hline Medical chart documentation error & 98 & 7.8 & 6 & 3.1 \\
\hline High dosage (1.5-10 times normal dosage) of & 80 & 6.4 & 23 & 11.9 \\
\hline \multicolumn{5}{|l|}{ medication with a normal therapeutic index } \\
\hline Drug without indication & 53 & 4.2 & 15 & 7.7 \\
\hline Error in the handling of a pharmaceutical form & 52 & 4.2 & 16 & 8.2 \\
\hline Drug dosage too low for patient's condition & 39 & 3.1 & 10 & 5.2 \\
\hline Inappropriate dosage interval & 31 & 2.5 & 8 & 4.1 \\
\hline Error in the time of administration & 23 & 1.8 & 2 & 1.0 \\
\hline Therapeutic duplication & 23 & 1.8 & 3 & 1.5 \\
\hline Interaction: association contraindicated & 19 & 1.5 & 4 & 2.1 \\
\hline Error in the switching to a medication included & 13 & 1.0 & 0 & 0.0 \\
\hline \multicolumn{5}{|l|}{ in the hospital drug guide } \\
\hline Nonformulary drug & 12 & 1.0 & 0 & 0.0 \\
\hline Inappropriate dosage form & 11 & 0.9 & I & 0.5 \\
\hline The drug may exacerbate the patient's condition & 3 & 0.2 & 3 & 1.5 \\
\hline \multicolumn{5}{|l|}{ (adverse effects or contraindications) } \\
\hline Documented allergy to a drug & I & 0.1 & I & 0.5 \\
\hline Error in the content of a secondary medicines & I & 0.1 & 0 & 0.0 \\
\hline \multicolumn{5}{|l|}{ package/refill error } \\
\hline Route of administration that can lead to mild toxicity & 1 & 0.1 & 0 & 0.0 \\
\hline Total & $\mid, 251$ & 100.0 & 194 & 100.0 \\
\hline \multicolumn{5}{|l|}{ Not associated with errors } \\
\hline Administration information for oral/subcutaneous/ & 2,389 & 74.6 & 447 & 67.2 \\
\hline \multicolumn{5}{|l|}{ inhalative medicines } \\
\hline Clarification of medical order or information request & 504 & 15.7 & 132 & 19.8 \\
\hline Medication plan explanation & 252 & 7.9 & 48 & 7.2 \\
\hline Information requested by physician or other health & 56 & 1.7 & 38 & 5.7 \\
\hline \multicolumn{5}{|l|}{ care professional from pharmacist } \\
\hline Total & 3,201 & 100.0 & 665 & 100.0 \\
\hline
\end{tabular}

The majority of the interventions carried out by clinical pharmacists were associated with errors categorized as significant $(68.1 \%, \mathrm{n}=1,570)$, followed by minor $(24.8 \%$, $\mathrm{n}=572)$ and serious errors $(7.2 \%, \mathrm{n}=165)$. Table 4 includes a description of the clinically serious errors detected in the study. No potentially lethal error was detected in our study. This same trend was found when considering every setting separately (Figure 1). Significant interventions were far more frequent than the other degrees of interventions in all the settings $(67.7 \%$ on the orthogeriatric ward at admission, $68.0 \%$ on the same ward at discharge, and $69.6 \%$ on the geriatric day unit). At discharge of the patients hospitalized on the orthogeriatric ward, the profile of the pharmacists' interventions was slightly less serious in comparison with the other settings.

In $65.1 \%$ of the patients who were admitted on to the orthogeriatric ward (283 patients), we could analyze the difference in the number of drugs at discharge and at
Table 4 Description of the clinically serious medication errors detected

\begin{tabular}{|c|c|c|}
\hline \multirow[t]{2}{*}{ Medication error } & \multirow{2}{*}{$\begin{array}{l}\text { Orthogeriatric } \\
\text { ward } \\
\mathrm{n}(\%)\end{array}$} & \multirow{2}{*}{$\begin{array}{l}\text { Geriatric } \\
\text { day unit } \\
\mathbf{n}(\%)\end{array}$} \\
\hline & & \\
\hline $\begin{array}{l}\text { Drug without indication (eg, doxycycline } \\
\text { prescribed as long-term medication) }\end{array}$ & $95(4.1)$ & $15(0.7)$ \\
\hline $\begin{array}{l}\text { Interaction: association contraindicated } \\
\text { (eg, amiodarone and haloperidol) }\end{array}$ & $29(1.3)$ & $4(0.2)$ \\
\hline $\begin{array}{l}\text { Drug may exacerbate the } \\
\text { patient's condition (warnings or } \\
\text { contraindications) (eg, spironolactone } \\
\text { and GFR }<30 \mathrm{~mL} / \mathrm{min} \text { ) }\end{array}$ & $16(0.7)$ & $3(0.1)$ \\
\hline $\begin{array}{l}\text { Documented allergy to a drug } \\
\text { (eg, acetylsalicylic acid prescribed in a } \\
\text { patient with an allergy to this drug) }\end{array}$ & I (0.04) & I (0.04) \\
\hline $\begin{array}{l}\text { Error in the content of a secondary } \\
\text { medicines package/refill error } \\
\text { (eg, L-Dopa/carbidopa retard and } \\
\text { not retard in the same package) }\end{array}$ & I (0.04) & $0(0.0)$ \\
\hline
\end{tabular}

Abbreviation: GFR, glomerular filtration rate. 


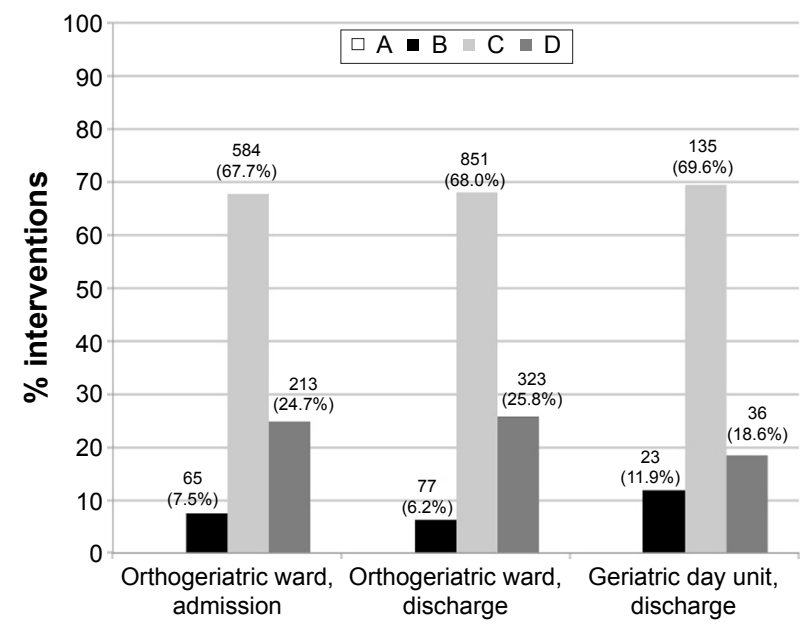

Figure I Severity of the medication errors detected on the three different settings: orthogeriatric ward at admission and discharge and on the geriatric day unit at discharge.

Notes: A, potentially lethal; B, serious; C, significant; D, minor; Category A is $0 \%$ in the three settings.

admission. The prescriptions of the remaining $34.9 \%$ could not be analyzed at discharge due to transfer to other units, death, or an earlier-than expected discharge from hospital. Of these patients, $77.4 \%$ were discharged with more drugs in comparison to the number of drugs at admission (18.4\% with one more drug, $15.2 \%$ with two more drugs, $12.7 \%$ with three more drugs, and $13.8 \%$ with four more drugs) (Figure 2). In $6.4 \%$ of the patients, there was no change in the number of drugs, and only $16.2 \%$ of the patients had a reduction in the total number of drugs they were taking before admission.

\section{Discussion}

Our findings show the importance of clinical pharmacist involvement in the optimization of pharmacotherapy in daily clinical practice. We found that in the majority of cases, the pharmacist's interventions had a significant impact

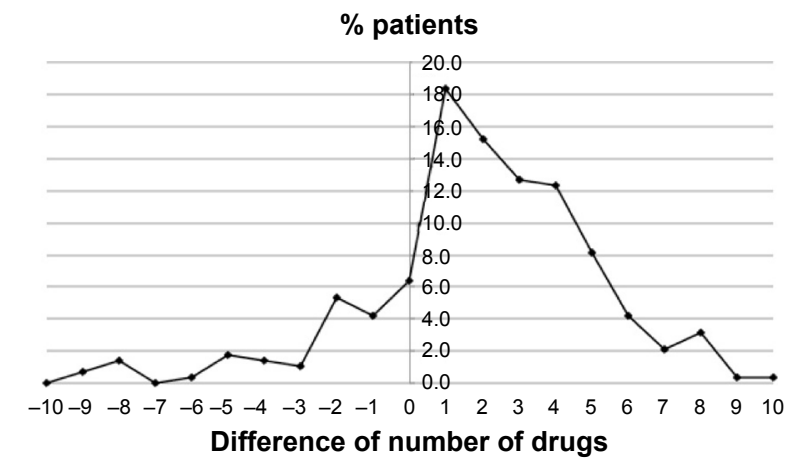

Figure 2 Difference of number of drugs (discharge-admission) of the patients who were admitted on to the orthogeriatric ward. on the patient's health. In this sense, we identified many opportunities to improve quality of care in older patients, a collective where a higher risk of medication errors is found. Moreover, we developed a triple approach to manage safety risks and optimize pharmacotherapy in these patients, which included validation of medical orders, medication reconciliation at admission, and a predischarge planning appointment with the patient. This approach could be helpful to improve procedures on geriatric wards. Finally, we described a systematic method for clinical pharmacists to record their clinical activities on geriatric wards.

The role of the pharmacists has evolved in the last decades from the preparation and delivery of medicinal products to a more active participation in patient care. The Joint Commission on Accreditation of Healthcare Organizations recommends that all medical orders are validated by a pharmacist before dispensing and that the outcomes are consequently recorded. ${ }^{20}$ Validation of medical orders before dispensing is currently a reality in few German hospitals, although awareness for this fact is gaining importance of recognition and some related studies have already been developed. . $^{21,22}$

Optimal management of medication regimens of older adults remains a challenge due to the still limited evidence for effective interventions. ${ }^{23}$ It is well known that the medication prescribed on surgery wards plays a secondary role in clinical practice and the physicians on these units are more aware of possible surgical errors and postoperative complications. ${ }^{21,24}$ Furthermore, the extensive definition of a medication error leads to the fact that, in different studies, different aspects of the definition are evaluated, leading to difficulty in comparing results between studies. ${ }^{2}$

In our study, the main reason for the pharmacist to make a recommendation associated with serious errors was a drug prescribed without indication, followed by contraindications (drug-drug or drug-disease interactions) and allergy to a drug inadvertently initiated during hospitalization. These three categories composed $7.1 \%$ of all the interventions. Similarly, in the study carried out by Poudel et al, ${ }^{25}$ recommendations carried out by geriatricians for withdrawal of a drug was conducted in $9.8 \%$ of all the medications analyzed, and Halvorsen et a ${ }^{26}$ found even higher rates.

With regard to the significant pharmaceutical interventions, clinically significant interactions were the most frequent in every setting, except for the orthopedic surgery unit at admission, where the omission of a drug from the medical order was slightly more frequent. Some studies ${ }^{10,27,28}$ have evaluated the importance of carrying out medication 
reconciliation at the patient's admission, where omission of drugs is one of the most frequent discrepancies detected in this process. ${ }^{27}$ The authors of this study point to the lack of training or experience, fatigue, and stress as error-provoking conditions, which lead to incomplete prescriptions at admission. A drug omitted from the medical order was also a very common error at the discharge of the patients, not only on the orthogeriatric ward but also on the day unit. Crotty et $\mathrm{al}^{29}$ showed that the addition of a pharmacist coordinator at discharge from hospital to a long-term care facility improves medication management. Over- and underdosing errors also played an important role in our study, which is in accordance with the results obtained by other authors. ${ }^{24,25,30}$ Transcribing errors on the administration charts, the fourth most significant error found, could easily be avoided by the implementation of tools such as computerized physician order entry.

Most of the pharmacist interventions conducted were classified as significant. A possible explanation of the lower severity of the interventions carried out at the discharge of the patients on the surgery unit might be that the medical orders of more than half of these patients had already been validated at their admission. Therefore, some serious medication errors could have been avoided by validating the medical order at the beginning of their hospitalization.

In view of the importance of the medication errors detected, it seems to be appropriate to include clinical pharmacists in health care teams to optimize the pharmacotherapy in older patients and to implement measures such as the development of clinical decision support systems. These tools have been proven to help reduce medication errors in geriatric patients. ${ }^{31,32}$

With regard to the predischarge appointment with the patients and their carers, a medication plan including information about the prescribed drugs such as therapeutic indication and administration was handed out and carefully explained to them. In this sense, pharmacists ensured at this point counseling on medication purpose and use, especially for high-risk medications such as antithrombotic or hypoglycemic agents, and medication therapy changes upon discharge.

Only $16.2 \%$ of the patients included in the study were discharged with fewer drugs than the number of drugs they were taking at admission. Some barriers for deprescribing are difficulty making decisions to stop medications, worry about withdrawing a drug prescribed by another physician, lack of knowledge about how to stop a medication, and concern about the consequences of stopping a drug. ${ }^{33}$ In the light of these results, an effort has to be made in order to improve deprescribing of unnecessary drugs in older patients. An approach to reduce inappropriate prescriptions in these patients has already been described. ${ }^{34}$

As expected, the degree of integration of the clinical pharmacist in the multidisciplinary team in terms of requests for information in both directions (pharmacist-physicians/nurses and physicians/nurses-pharmacist) was higher on the geriatric day unit due to the permanent presence of the pharmacist there. The physical closeness between health care professionals was in this case crucial to improve cooperation.

One limitation in this study was that the medicines involved in each intervention were not recorded. However, the main limitation was that the degree of acceptance of the pharmaceutical intervention could not be assessed due to lack of resources to track the physicians' decisions after the recommendations were made.

\section{Conclusion}

We demonstrated that pharmacists' interventions (medication review and a planning intervention at admission and at discharge) have a positive effect on prescribing in older adults, ensuring that they receive effective, safe, and efficient drug therapy. This study allowed pharmacists to design a pharmaceutical care model that unifies activities around the geriatric patient and within the multidisciplinary team. Further work needs to be done for geriatric clinical pharmacists in Germany.

\section{Acknowledgments}

The study was supported by a grant from Schöller-Stiftung, Doctor Theo und Friedl Schöller Forschungszentrum für Wirtschaft und Gesellschaft. We are particularly grateful to the pharmacy students who collaborated in this study, directly (Olesia Edel, Jannica Nietzke, Julia Bergmann, and Karina Gerbersdorf) and indirectly (Carmen Schönwiesner and Andreas Eichert). We would like to thank Cecilia Martínez Fernández-Llamazares (Hospital General Universitario Gregorio Maranón, Madrid, Spain) for her expert advice and Jenny Rudland for editorial assistance. The current address of Lucía Cortejoso is Department of Pharmacy, University Hospital Dresden, Germany.

\section{Disclosure}

The authors report no conflicts of interest in this work.

\section{References}

1. Suggested definitions and relationships among medication misadventures, medication errors, adverse drug events, and adverse drug reactions. Am J Health Syst Pharm. 1998;55(2):165-166. 
2. Alhawassi TM, Krass I, Bajorek BV, Pont LG. A systematic review of the prevalence and risk factors for adverse drug reactions in the elderly in the acute care setting. Clin Interv Aging. 2014;9:2079-2086.

3. Junius-Walker U, Theile G, Hummers-Pradier E. Prevalence and predictors of polypharmacy among older primary care patients in Germany. Fam Pract. 2007;24(1):14-19.

4. Reeve E, To J, Hendrix I, Shakib S, Roberts MS, Wiese MD. Patient barriers to and enablers of deprescribing: a systematic review. Drugs Aging. 2013;30(10):793-807.

5. Garfinkel D, Mangin D. Feasibility study of a systematic approach for discontinuation of multiple medications in older adults: addressing polypharmacy. Arch Intern Med. 2010;170(18):1648-1654.

6. Spinewine A, Dhillon S, Mallet L, Tulkens PM, Wilmotte L, Swine C. Implementation of ward-based clinical pharmacy services in Belgium description of the impact on a geriatric unit. Ann Pharmacother. 2006; 40(4):720-728.

7. Spinewine A, Swine C, Dhillon S, et al. Effect of a collaborative approach on the quality of prescribing for geriatric inpatients: a randomized, controlled trial. J Am Geriatr Soc. 2007;55(5):658-665.

8. Kaboli PJ, Hoth AB, McClimon BJ, Schnipper JL. Clinical pharmacists and inpatient medical care: a systematic review. Arch Intern Med. 2006; 166(9):955-964

9. Coleman EA, Smith JD, Raha D, Min S. Posthospital medication discrepancies: prevalence and contributing factors. Arch Intern Med. 2005; 165(16): 1842-1847.

10. Boockvar KS, Carlson LaCorte H, Giambanco V, Fridman B, Siu A. Medication reconciliation for reducing drug-discrepancy adverse events. Am J Geriatr Pharmacother. 2006;4(3):236-243.

11. Coleman EA. Falling through the cracks: challenges and opportunities for improving transitional care for persons with continuous complex care needs. J Am Geriatr Soc. 2003;51(4):549-555.

12. Gardella JE, Cardwell TB, Nnadi M. Improving medication safety with accurate preadmission medication lists and postdischarge education. Jt Comm J Qual Patient Saf. 2012;38(10):452-458.

13. Lee Y-Y, Kuo L-N, Chiang Y-C, et al. Pharmacist-conducted medication reconciliation at hospital admission using information technology in Taiwan. Int J Med Inform. 2013;82(6):522-527.

14. Galvin M, Jago-Byrne M-C, Fitzsimons M, Grimes T. Clinical pharmacist's contribution to medication reconciliation on admission to hospital in Ireland. Int J Clin Pharm. 2013;35(1):14-21.

15. Tam VC, Knowles SR, Cornish PL, Fine N, Marchesano R, Etchells EE. Frequency, type and clinical importance of medication history errors at admission to hospital: a systematic review. CMAJ. 2005;173(5): $510-515$.

16. Dedhia P, Kravet S, Bulger J, et al. A quality improvement intervention to facilitate the transition of older adults from three hospitals back to their homes. J Am Geriatr Soc. 2009;57(9):1540-1546.

17. Singler K, Biber R, Wicklein S, Heppner HJ, Sieber CC, Bail HJ. "N-active": a new comanaged, orthogeriatric ward: observations and prospects. Z Gerontol Geriatr. 2011;44(6):368-374.

18. Hofmann G, Rapke C, Scherbel G, Stedtfeld H-W. Einbindung eines Apothekendokuments in die elektronische Patientenakte [Incorporation of a pharmacy document in the electronic patient record]. Krankenhauspharmazie. 2007;28:396-400.
19. Fernández-Llamazares CM, Pozas M, Feal B, et al. Profile of prescribing errors detected by clinical pharmacists in paediatric hospitals in Spain. Int J Clin Pharm. 2013;35(4):638-646.

20. Rich DS. New JCAHO medication management standards for 2004. Am J Health Syst Pharm. 2004;61(13):1349-1358.

21. Langebrake C, Ihbe-Heffinger A, Leichenberg K, et al. Nationwide evaluation of day-to-day clinical pharmacists' interventions in German hospitals. Pharmacotherapy. 2015;35(4):370-379.

22. Langebrake $\mathrm{C}$, Hilgarth $\mathrm{H}$. Clinical pharmacists' interventions in a German university hospital. Pharm World Sci. 2010;32(2):194-199.

23. Howard R, Avery T. Inappropriate prescribing in older people. Age Ageing. 2004;33(6):530-532.

24. Rapke C, Hofmann G, Stedtfeld H-W, Scherbel G. Erfassung und Revision von Fehlern bei der extern verordneten Begleitmedikation unfallchirurgischer Patienten durch Kooperation von Arzt und Apotheker. Eine Studie zur Qualitätssicherung. [Cooperation between physician and pharmacist to determine and resolve errors in concomitant medication previously prescribed for trauma patients. Quality assurance study]. Unfallchirurg. 2004;107(11):1041-1049.

25. Poudel A, Peel NM, Mitchell CA, Gray LC, Nissen LM, Hubbard RE. Geriatrician interventions on medication prescribing for frail older people in residential aged care facilities. Clin Interv Aging. 2015;10: 1043-1051.

26. Halvorsen KH, Ruths S, Granas AG, Viktil KK. Multidisciplinary intervention to identify and resolve drug-related problems in Norwegian nursing homes. Scand J Prim Health Care. 2010;28(2):82-88.

27. Buck TC, Gronkjaer LS, Duckert M-L, Rosholm J-U, Aagaard L. Medication reconciliation and prescribing reviews by pharmacy technicians in a geriatric ward. J Res Pharm Pract. 2013;2(4):145-150.

28. Beckett RD, Crank CW, Wehmeyer A. Effectiveness and feasibility of pharmacist-led admission medication reconciliation for geriatric patients. J Pharm Pract. 2012;25(2):136-141.

29. Crotty M, Rowett D, Spurling L, Giles LC, Phillips PA. Does the addition of a pharmacist transition coordinator improve evidence-based medication management and health outcomes in older adults moving from the hospital to a long-term care facility? Results of a randomized, controlled trial. Am J Geriatr Pharmacother. 2004;2(4):257-264.

30. Al Rahbi HAM, Al-Sabri RM, Chitme HR. Interventions by pharmacists in out-patient pharmaceutical care. Saudi Pharm J. 2014;22(2): 101-106.

31. Hornick TR, Higgins PA, Stollings C, Wetzel L, Barzilai K, Wolpaw D. Initial evaluation of a computer-based medication management tool in a geriatric clinic. Am J Geriatr Pharmacother. 2006;4(1):62-69.

32. Kaur S, Mitchell G, Vitetta L, Roberts MS. Interventions that can reduce inappropriate prescribing in the elderly: a systematic review. Drugs Aging. 2009;26(12):1013-1028.

33. Anthierens S, Tansens A, Petrovic M, Christiaens T. Qualitative insights into general practitioners views on polypharmacy. BMC Fam Pract. 2010;11:65.

34. Martin P, Tamblyn R, Ahmed S, Benedetti A, Tannenbaum C. A consumer-targeted, pharmacist-led, educational intervention to reduce inappropriate medication use in community older adults (D-PRESCRIBE trial): study protocol for a cluster randomized controlled trial. Trials. 2015;16:266.
Clinical Interventions in Aging

\section{Publish your work in this journal}

Clinical Interventions in Aging is an international, peer-reviewed journal focusing on evidence-based reports on the value or lack thereof of treatments intended to prevent or delay the onset of maladaptive correlates of aging in human beings. This journal is indexed on PubMed Central, MedLine,

\section{Dovepress}

CAS, Scopus and the Elsevier Bibliographic databases. The manuscript management system is completely online and includes a very quick and fair peer-review system, which is all easy to use. Visit http://www.dovepress. com/testimonials.php to read real quotes from published authors. 